\title{
Degree of leaming and transfer of training
}

L. R. GOULET

WEST VIRGINIA UNIVERSITY

Transfer of training as a function of first list leaming was studied using the A-B, A-C paired-associate paradigm. Degree of learning on the first list was defined in terms of the number of practice trials (5 trials, 10 trials, trials to one perfect repetition) on the complete list and in terms of the degree of learning of individual pairs within the list. The degree of learning of individual pairs on the first list was manipulated by incorporating the \% ORM technique of partial reinforcement $(100,60$, and $20 \% \mathrm{ORM})$. The results indicated that negative transfer in the $\mathrm{A}-\mathrm{B}, \mathrm{A}-\mathrm{C}$ paradigm (as compared to the $A-B, C-D$ control paradigm) was a direct function of the number of practice trials but was not related to \% ORM level. Implications of these results were discussed.

Recent evidence (Postman, 1962) suggests that transfer of training under the $A-B, A-C$ paradigm is a U-function of the amount of practice on the first list. Postman found increasing negative transfer after moderate degrees of List 1 learning (no overlearning trials) with a reduction in negative transfer where List 1 was practiced beyond mastery. However, the trend noted by Postman was not statistically reliable. For this reason, further study of the effects of first list practice on transfer of training is warranted.

Additional experimental study of the List 1 learningtransfer function is also important because of a potential source of confounding. For example, when practice is discontinued prior to List 1 mastery (e.g., $3 / 9,6 / 9$, etc.), the easiest pairs are learned (and overlearned) with the more difficult pairs not being learned. This result suggests a possible confounding of List 1 practice with individual pair difficulty. In fact, even when List 1 learning is carried to criterion (e.g., 9/9), there is differential overlearning of the easiest pairs.

The present experiment was an attempt to assess transfer effects under the $A-B, A-C$ paradigm as a function of degree of List 1 practice defined both in terms of the number of practice trials of the complete list and also in terms of individual pair overlearning. The learning of individual pairs was manipulated by incorporating the technique of partial reinforcement (\% ORM), which assured differential degrees of learning for individual pairs while still holding the total number of practice trials constant. The technique of $\%$ ORM (percentage of occurrence of response members) involves deleting the response terms on a fixed percentage of the learning trials, a procedure which effectively retards both response learning and associative learning (Goulet \& Solso, 1966; Schulz, 1965) in direct proportion to the percentage of trials that the responses are deleted on the learning trials.

\section{Design}

The basic design was a 3 by 2 by 3 mixed factorial with List 1 \% ORM $(100 \%, 60 \%, 20 \%)$ as a mixed-list factor, and paradigm (A-B, A-C, experimental; $A-B$, $C-D$, control), and List 1 practice (five trials, $5 \mathrm{~T}$; ten trials, 10T; one perfect trial, 1P) as between-S factors. Following Goulet and Solso, \% ORM partial reinforcement was manipulated such that three pairs each in List 1 were randomly assigned to the $20 \%$, $60 \%$, and $100 \%$ levels. The responses under $20 \%$ ORM were paired with stimuli once per block of five trials while those in the $60 \%$ and $100 \%$ ORM levels were paired three and five times per block of five trials, respectively. As a further control for pair difficulty, alternate lists were constructed such that each pair was assigned to the $20 \%, 60 \%$, and $100 \%$ ORM levels in different lists. All lists consisted of nine paired adjectives (low similarity) taken from Haagen (1949). List 2 was identical for all groups and did not involve partial reinforcement.

\section{Procedure}

The Ss were 72 general psychology students who were randomly assigned to treatments with the restriction that equal numbers be assigned to each treatment before another replication block was begun. The lists were presented in six random orders on a Stowe memory drum at a 2:2 sec rate with a $4-\mathrm{sec}$ intertrial interval. List 2 was practiced for 10 trials or to a criterion of one errorless trial, whichever occurred last. To assure attention to the stimulus terms when the responses were deleted (Goulet, 1966), the Ss were asked to pronounce each stimulus and response when they appeared in the window of the drum. Results and Discussion

List $l$ and List 2 learning. Learning varied directly with $\%$ ORM on List 1 . Inspection of the data revealed essentially identical learning rates for all groups on the early trials. The list was learned to criterion in the 1P A-B, A-C and A-B, C-D treatments in 18.00 and 21.75 trials, respectively.

Table 1 provides summary data for List 2 learning for each treatment. For the A-B, A-C paradigm, means are presented at each level of List 1 practice and \% ORM. For the A-B, C-D paradigm the means

Table 1 Mean Correct Anticipations on Trials 1-5

\begin{tabular}{ccccccc} 
& \multicolumn{8}{c}{ A-B, A-C } & & Paradigm \\
& & $20 \%$ ORM & $60 \%$ ORM & $100 \%$ ORM & Total & Total \\
List 1 & $5 T$ & 7.08 & 4.83 & 5.17 & 17.08 & 15.25 \\
Practice & 10T & 5.00 & 5.17 & 4.67 & 14.84 & 17.67 \\
& IP & 6.75 & 5.83 & 5.58 & 18.16 & 27.92
\end{tabular}


represent learning for the entire list, independently of List $1 \%$ ORM, since the List 2 pairs could not legitimately be identified with a particular List 1 $\%$ ORM level. The first analysis involved a comparison of mean correct responses on Trials 1-5 for the $A-B, A-C$ and $A-B, C-D$ paradigms at each level of List 1 learning. For this analysis, the effects of practice and practice by paradigm were statistically significant $(F=6.12, \mathrm{df}=2 / 66, \mathrm{p}<.005$, and $\mathrm{F}=3.34$, $\mathrm{df}=2 / 66, \mathrm{p}<.05)$. The paradigm effect approached significance $(F=3.79, \mathrm{df}=1 / 66, p<.10)$. Rate of learning decreased, then increased as a function of List 1 practice for the $A-B, A-C$ paradigm and increased directly with first list practice under the $A-B, C-D$ paradigm. Additionally, learning was better for the $A-B, A-C$ paradigm than for the $A-B, C-D$ paradigm (positive transfer) after five trials of List 1 practice, while negative transfer occurred under the other levels of practice.

The data were also analyzed to determine the effects of \% ORM on transfer under the A-B, A-C paradigm. Difference scores were determined by subtracting the mean correct responses/3 under the $A-B, C-D$ paradigm from each $S$ 's score for each level of $\%$ ORM under the A-B, A-C paradigm. Only the effects of practice reached statistical significance $(F=7.96, \mathrm{df}=2 / 66, \mathrm{p}<.001)$. Neither the effect of $\%$ ORM nor the interaction was pronounced $(\mathrm{F}=\mathbf{2 . 1 9}$, $\mathrm{df}=2 / 66, \mathrm{p}>.05$ and $F=2.11, \mathrm{df}=4 / 66, \mathrm{p}>.05)$. The data essentially reflect increasing negative transfer as a function of List 1 practice. As will be noted from Table 1, the trend toward increasing negative transfer was also apparent as \% ORM increased although the effect was slight. Finally, learning was compared under each level of \% ORM and level of practice for Ss learning under the A-B, A-C paradigm (Table 1). No effects approached significance in this analysis.

The data in the present experiment confirm those obtained by Postman, who found that negative transfer (E-C) increased directly with first list practice as long as no overlearning trials were provided. Postman also found that absolute performance under the A-B, A-C paradigm was unaffected by the degree of first list practice. This result, which was also found in the present study, presumably reflects a counterbalancing of facilitative, non-specific (e.g., learningto-learn and warm-up) and inhibitory, specific (asso- ciative interference) transfer factors in this paradigm.

Surprisingly, no effect was found for \% ORM, nor did \% ORM interact with level of practice. The data, therefore, support a conclusion that the absolute number of practice trials (rather than specific pair learning) constitutes the major source of variance in determining the List 1 learning-transfer function. Mandler (1954) has favored a similar conclusion in discussing the effects of first list overlearning on transfer of training.

As was noted, there was no tendency for negative transfer to increase and then decrease as a U-function with increasing first list practice. However, first list practice was not continued beyond mastery in the present study. It is likely that a decrease in negative transfer would have been demonstrated had some overlearning trials been given (e.g., Postman, 1962). Postman has also noted the likely sources of transfer effects in studies comparable to the present one. These were learning-to-learn and warm-up, associative interference, and differentiatiation between the lists. It is possible that the latter variable, list differentiation, is operative primarily after overlearning trials. In any event, list-differentiation would be expected to be minimal if first list practice were discontinued prior to mastery.

\section{References}

Goulet, L. R., \& Solso, R. L. Percentage occurrences of stimulus members and meaningfulness as related to forward and backward recall of paired-associates. J. exp. Psychol., 1966, 71, 494-498.

Goulet, L. R. Associative and free recall of paired-associates under conditions of response articulation and \% OSM partial reinforcement. Psychon. Sci., 1966, 5, 227-228.

Haagen, C. H. Synonymity, vividness, familiarity and association values for 400 pairs of common adjectives. J. Psychol, 1949 , $30,185-200$.

Mandler, G. Response factors in human learning. Psychol. Rev., $1954,61,235-244$.

Postman, L. Transfer of training as a function of experimental paradigm and degree of first-list learning. J. verbal Learn. verbal Bchav., 1962, 1, 109-118.

Schulz, R. W. Learning of paired-associates as a function of pronounciability and percentage occurrence of stimulus members. J. ierbal Learn. verbal Behav., 1965, 4, 494-497.

\section{Note}

1. The present research was supported by NIMH grant MH 13130-01 to the author. Appreciation is expressed to Richard Meltzer and Kathleen O'Shaunessy who ran the Ss and participated in the data analysis. 